\title{
Review of Jean Kazez's Animalkind: What We Owe to Animals
}

\author{
James K. Stanescu \\ Department of Communication Studies and Theatre \\ Mercer University \\ stanescu_jk@mercer.edu
}

\section{Book Review}

Jean Kazez's 2010 book Animalkind: What We Owe To Animals manages to breath a bit of fresh air into many of the debates over our ethical duties and commitments toward other animals. Not only that, but Kazez has a dry wit that is often on display throughout the book, causing the reader to burst out into unexpected laughter. Animalkind is a broad ranging book, taking on issues such as excuses we give for killing animals, philosophical and religious distinctions that give us the right to do whatever we wish to animals, animal consciousness and capacities with their implications for ethics, equality between humans and animals, cavemen hunting, factory farming, scientific experimentation on animals, and the ecological destruction of habitats for all beings. While clearly articulated and excellent for introductory students, many of the arguments and examples in the book will not come as a surprise to anyone who has read the classic books on our ethical obligations toward animals. However, after the first few chapters Kazez begins to slowly work out her unique contribution to the field.

Kazez points out that etymologically speaking, kindness, kind, and kin all "share a common origin, the old English cynd" (p. 30). This etymology hints that we give kindness to our own kind, our own kin. It is around this question of kindness, kind, and kin we can best situate Kazez's Animalkind. As the title implies, Kazez is very concerned with extending our kindness to other animals. However, unlike many other thinkers on animal ethics, it is to our fellow human kin to whom we explicitly owe the most kindness. This is, in many ways, Kazez's contribution to animal ethics. If you look at Peter 
Singer's Animal Liberation, you see an argument for the equal consideration of interests for all sentient beings. If you look at Tom Regan's The Case for Animal Rights, you see an argument for treating equally all beings that are subjects of life. In both cases, extending our ethical obligations to other animals has entailed having them enter into the community of ethical patients as equals with all other ethical patients. While Kazez wants us to take the issues of animals seriously, she believes that equality is not a viable option for our ethical commitment toward animals. And, as Kazez herself points out, while philosophers like Singer may articulate a ground for preferring humans in most instances, such preference is based on other animals having different interests or different levels of interests than humans. However, we still have to equally consider those interests. Kazez's distinction is more fundamental.

Following up on the work of David DeGrazia, she argues for "a sliding scale model" of ethics (p. 93). Kazez defines this model thusly:

Two individuals can both have a right to be treated with respect, but one can have more respect due to him than the other. One can simply be deserving of more respect. Having the same right makes them out to be equals. But if there is a big difference in the respect they deserve, inequality lurks under the surface. This is not radical inequality-one gets infinite respect and the other none. We are looking again at the possibility of a sliding scale model [...], with respect being proportioned to capacities (p. 103).

This model seeks simultaneously to argue for our need to consider animals in our ethical decisions, but also to exclude animals from being equal to humans in those considerations. Kazez furthers her argument, not by creating rigorous philosophical distinction, but rather by employing more intuitive concepts such as respect, but also "care, concern, and compassion" (p. 113). Unlike sentience for Singer, or a subject of life for Regan, what calls us to respect and what duties are entailed in respect are never clearly defined. This ambiguity around respect is both the concept's strength and weakness. Kazez is very clear that ethical relationships require comparative judgments, 
while at the same time resisting the sort of orderly calculations one might find in certain kinds of utilitarianism. Instead, comparative judgments are about facing situations that entail an honest and real conflict of interest. Much of the book is centered on a series of these concrete conflicts that help Kazez work out these theories of sliding scale model of ethics, respect, and comparative judgments.

Part of what makes Animalkind refreshing is Kazez's ability to liven up the particularly stale trope of the lifeboat scenario. The lifeboat scenario involves discussions about if humans and animals were trapped in a lifeboat, and one had to be killed in order to safeguard the others, who gets chosen. The situation, already wellworn and always a bit fantastical in its various iterations, are given a level of concrete reality by Kazez. While some of her scenarios are still in the fantastical realm (like "pangfish", fish with no sense of consciousness that are capable of feeling small amounts of pain), she mostly sticks to contemporary and realistic situations. Thus, we are asked how we should have responded to buses helping to get people out of New Orleans after Hurricane Katrina. Such buses had a strict "humans only" policy. Kazez, while agreeing that we need to have plans in place for animals during disaster relief, largely agrees with the "human only" policies. She also agrees that cavemen needing to hunt for survival should be able to kill aurochs, but that our modern factory farming system is unacceptable. She believes that experimenting on monkeys to develop the polio vaccine was necessary, but that Harry Harlow's notorious experiments on monkeys violate every notion of respect. In each case she both pushes back against the notion of equality between humans and other animals, while also pushing back against the idea that animals are not deserving of basic respect and protections. Kazez believes that these scenarios either put as a lie, no matter how well intentioned, the relationship between humans and other animals, or open us up to a far more radical stance than many people would be willing to accept on the issue of animal ethics. But if the ambiguous nature of respect allows it the flexibility to confront moments of comparative judgment, it also opens the concept up to accusations of speciesism. 
Respect seems to follow intuitive and commonsensical rules about the treatment of others, including other animals. So, most people would agree that Harlow's experiments were barbaric or that factory farming is horrific. At the same time, most people would agree that the weakest and dumbest human deserves more respect and protection than the most capable and intelligent animal. Arguments for an animal ever being more important than a human would be, by their very nature, counter-intuitive. And this where the problem of speciesism rears its ugly little head. Speciesism is the argument that a certain species, usually humans, are ipso facto more important than any other species. Because we live in a culture so thoroughly sutured by speciesism, our intuitive response about who and what deserves the most respect is always going to be fellow humans, and the criteria for that respect will almost always be how much like a human another animal is. And it isn't that Kazez doesn't address the issue of speciesism; it is rather that her conclusions are different from those of philosophers like Peter Singer who have traditionally advanced criticisms of speciesism. So, Kazez concludes, "If we are without prejudice, we will not see vast differences separating men and women, blacks and whites. But if we are without prejudice against animals, surely we will still see vast differences (p. 81, emphasis in original)." For Kazez, having different levels of respect for animals are not instances of irrational bias, but rather "simply being realistic" (p. 81). This is exactly where the issue of speciesism meets the ethical principle of equality.

No one who supports equality is ever doing so on the basis of actual equality of any being to any being. We are all different, filled with vastly different capabilities and attitudes, different histories and futures. The principle of equality is not that we are the same and without difference, but rather those differences shouldn't entail us to higher levels of ethical consideration. Just because someone is an amazing pianist doesn't mean she should be given more protections and support than someone incapable of playing an instrument. Just because someone is a genius doesn't mean she deserves less medical attention than someone who is below average intelligence. The 
differences, while real, don't justify different ethical obligations from society or individuals. People who argue for equality in ethical formulations don't do so because they don't believe there are not meaningful differences between individuals, but rather because not having equality leads us to the sort of hierarchical relationship of people's lives that should give us all pause, and even shame. When philosophers like Peter Singer make arguments from marginal cases, they are not just trying to make us question why we give more respect to one species rather than another, but also to warn us that not avowing equality leads us to shaky ethical ground. To give one example from Animalkind, when referencing the polio vaccine that was originally tested on animals, she notes, "the next group of guinea pigs were two groups of children living in 'homes' for the mentally and physically disabled" (p. 140). It is hard not to see the connection there, that the same lack of equality that allow the polio vaccine to be developed on animals also allowed it to be tested originally on some of the most vulnerable human members of our society. Likewise, pointing to laws that allowed antebellum slavery to thrive as an example of how we can treat animals as property, but as a specially protected kind of property, is not going to be much assurance for those of us who worry about the treatment of animals, especially because Kazez herself recognizes that "[s]uch laws were not enforced often" (p. 120). Those who advocate equality do so not because they do not believe there are differences, but because they seek to avoid things like testing on disabled orphans or laws that allowed for slavery.

People who feel that the equality between humans and other animals is an axiomatic condition for successful ethics relations will find much to object to in Animalkind. However, Kazez challenges us to explore more deeply issues of comparative judgment that challenge such beliefs, and she does so in ways that seem both sincere and realistic. People who want a framework to help animals but are wary of traditional arguments for animal ethics will find Animalkind a fun and interesting read. And whatever the reader's stance, it is worth noting that if we follow the principles that Kazez lays out, the vast 
majority of violence we do to other animals would need to be eliminated. Animalkind's clarity, thoroughness, and accessibility make it a wonderful text for students just beginning to address issues on animal ethics, and its well-woven challenges to traditional models of animal ethics means it needs to be read and contended with by the rest of us. 